\title{
Prognosis in acute pancreatitis
}

\author{
Bechien U. Wu MD MPH
}

$\mathrm{S}$ ince the original Ranson criteria were published more than 30 years ago, ${ }^{1}$ few topics have engendered as much sustained interest as the prediction of outcome in acute pancreatitis. Acute pancreatitis is a common cause for admission to hospital, accounting for more than 200000 admissions in the United Stated annually. ${ }^{2}$ Although most patients with acute pancreatitis will recover without sequelae, between $10 \%$ and $20 \%$ will have a more complicated clinical course with a higher risk of morbidity and mortality. ${ }^{3}$

This review provides a summary of recent developments in early risk assessment in acute pancreatitis, emphasizing the parameters that may be useful in the management of this condition. The evidence underpinning this review is primarily based on findings from recently published observational cohort studies. Although not a systematic review, this article will focus on risk assessment strategies that have been externally validated in the literature.

\section{How can prognosis be determined?}

The two most common approaches to determining prognosis in acute pancreatitis are use of a clinical scoring system and measurement of specific laboratory tests. These prognostic markers should not be confused with the actual measures of severity that are used to classify the degree of illness a patient has. Measures of severity in acute pancreatitis were defined in the Atlanta classification system. These include either local complications (e.g., necrosis and acute collection of fluid) or persistent organ failure (e.g., shock, respiratory failure or renal insufficiency). ${ }^{4}$

When evaluating prognosis in acute pancreatitis, it is also important to consider the outcome that one is trying to predict and when such a prediction should be made. Most studies that evaluate prediction methods in acute pancreatitis have focused on death as the outcome of interest because it is a well-defined, clinically significant outcome. However, recent data from the US National Center for Health Statistics suggest that overall mortality has declined over the past several decades, with estimates ranging from $1 \%-5 \% .^{5}$ This has led to increased debate over whether death remains the most appropriate outcome to use when predicting the outcome of acute pancreatitis.

With respect to the timing of prediction, it is now clear that the first 24 hours after admission to hospital are critical. In a retrospective cohort study conducted across 159 intensive care units (ICUs) in the United Kingdom, $75 \%$ of patients with acute pancreatitis who required intensive care were transferred to the ICU within the first 72 hours of admission to hospital, with a median time-to-transfer of 24 hours after admission. ${ }^{6}$ To be of the greatest value to clinicians, predictions of outcome should be accurately and reliably applied as early as possible, preferably during the first 24 hours of admission to hospital. A prediction tool should also have a high level of sensitivity; underestimating the severity of pancreatitis can have life-threatening consequences.

\section{Scoring systems}

The most widely used index for early risk stratification is the Acute Physiology and Chronic Health Examination (APACHE) II. ${ }^{7}$ Although more recent iterations of this scoring system have been developed, the advantages of the APACHE II are its familiarity, objective nature, and ability to be calculated at any time during a patient's stay in hospital. This scoring system has been widely validated for predicting death in acute pancreatitis. Most practice guidelines recommend a cut-off score of more than eight points at admission for prediction of severe disease, although several prospective observational studies have shown that specificity can be increased by raising the threshold to 10 points or more at admission (specificity $66 \%-81 \%$ ). ${ }^{8.9}$

Use of the APACHE II in clinical practice has

\section{KEY POINTS}

- An accurate determination of prognosis during the early management of acute pancreatitis is an important opportunity for intervention.

- Both clinical scoring systems and individual laboratory tests can be used to help predict outcome during the early phase of illness.

- Recent attention has focused on optimizing routine tests to help guide resuscitation efforts.
Competing interests: None declared.

This article was commissioned and has been peer reviewed.

Correspondence to: Dr. Bechien U. Wu, buwu@partners.org

CMAJ 2011. DOI:10.1503 /cmaj.101433 
several important limitations, such as the requirement for multiple parameters and the need for an online calculator (versions of which are widely available on the Internet). As a result, several additional scoring systems have been developed for bedside application. The modified Glasgow score was developed in the mid-1980s..$^{10}$ This scoring system, which incorporates seven routine laboratory tests, as well as the patient's age, has been widely validated for the prediction of outcome in acute pancreatitis. Although simpler to use than the original Ranson criteria, the modified Glasgow score was similarly designed to be calculated 48 hours after admission to hospital. As previously noted, this may miss a potentially important therapeutic window.

A more recent scoring system developed for use during the first 24 hours of admission to hospital is the Bedside Index of Severity in Acute Pancreatitis (BISAP). ${ }^{3}$ This score was derived using data from a population of 17992 patients and validated on a population of 18256 patients in the United States. This five-factor scoring system (Box 1) was shown to have similar accuracy to the APACHE II for predicting death (area under the receiver operating characteristic [ROC] curve 0.82 ) in the initial retrospective study and in several subsequent prospective cohort studies. ${ }^{11,12}$ The BISAP is a simplified scoring system that can be easily applied in the earliest phases of acute pancreatitis to help identify which patients have an increased risk of death.

There has been interest in determining to what extent the development of systemic inflammatory response syndrome alone (Box 2) can be used to determine prognosis in acute pancreatitis. ${ }^{13-15}$ This four-factor syndrome, diagnosed on the basis of vital signs and the leukocyte count, first emerged from the literature on sepsis. ${ }^{16}$ Although the presence of the syndrome during the first 24 hours of admission to hospital has high sensitivities for predicting organ failure $(85 \%)$ and death (100\%), it lacks specificity for severe disease $(41 \%)$. Specificity is increased with the duration of the syndrome, such that per-

\section{Box 1: Scoring system for Bedside Index of Severity in Acute Pancreatitis (BISAP) ${ }^{3}$}

Score one point for each of the following criteria:

- Blood urea nitrogen level > $8.9 \mathrm{mmol} / \mathrm{L}$

- Impaired mental status

- Systemic inflammatory response syndrome is present (see Box 2)

- Age > $60 \mathrm{yr}$

- Pleural effusion on radiography

A score of more than three indicates an increased risk of death. sistent systemic inflammatory response syndrome (i.e., longer than 48 hours) has been linked with adverse outcomes that include organ dysfunction and death. ${ }^{14}$

\section{Laboratory tests}

A key advantage of using laboratory tests to determine prognosis is the potential to monitor a patient's initial response to treatment. For patients with acute pancreatitis, initial treatment primarily consists of fluid resuscitation. Several routine laboratory tests have been proposed as possible predictors of outcome: serum hematocrit, serum creatinine and blood urea nitrogen levels. Results of several small single-centre studies in the late 1990s and early 2000s suggested that an elevated hematocrit or "hemoconcentration" at admission was a predictor of pancreatic necrosis. ${ }^{17,18}$ Unfortunately, the accuracy of hematocrit as a prognostic indicator of necrosis was not confirmed in several subsequent external validation studies. ${ }^{19-21}$ More recently, attention has focused on early changes in serum creatinine levels. $^{22}$

Recent data suggest that serial measurement of blood urea nitrogen levels is the most useful routine laboratory test for determining risk of death. In a large retrospective cohort study conducted at 69 US hospitals, the levels of blood urea nitrogen at admission and during the first 24 hours of a patient's stay in hopital were found to be more accurate predictors of death than other routine laboratory tests (leukocyte count and glucose, hemoglobin and creatinine levels) ${ }^{23}$ with an area under the ROC curve similar to that of the APACHE II. The prognostic accuracy of serial measurement of blood urea nitrogen levels has since been validated using data from three independent prospective cohort studies. ${ }^{24}$

Several markers of systemic inflammation have also been studied as potential biomarkers to help predict the outcome of acute pancreatitis. The most widely available and well studied is the acute-phase reactant, C-reactive protein. Several

\section{Box 2: How to determine if systemic inflammatory response syndrome is present ${ }^{13,14}$}

Systemic inflammatory response syndrome is present if two or more of the following criteria are met:

- Heart rate $>90$ beats/min

- Respiration rate $>20$ breaths/min or partial pressure of carbon dioxide is $<32 \mathrm{~mm} \mathrm{Hg}$

- Body temperature $<36^{\circ} \mathrm{C}$ or $>38^{\circ} \mathrm{C}$

- Leukocyte count $<4$ or $>12 \leftrightarrow 10^{\circ} / \mathrm{L}$, or $>10 \%$ immature neutrophils (bands) 
observational studies have shown that C-reactive protein levels peak on day three after the start of symptoms and have their greatest prognostic value 48 hours after the start of symptoms. ${ }^{25}$ Unfortunately, this timeline limits the usefulness of measuring C-reactive protein levels during the initial treatment phase of acute pancreatitis.

Procalcitonin, polymorphonuclear elastase, and interleukins 6 and 8 have each been shown to have a high degree of accuracy in several prospective observational cohort studies. ${ }^{25}$ Although potentially valuable for investigational purposes, none of these parameters is widely available for routine clinical use in North America.

Markers of protease activation have also been extensively studied as early predictors of outcome in acute pancreatitis. The most well established is urine trypsinogen-activation peptide, which has been shown to be both an accurate and reliable early prognostic indicator. ${ }^{26}$ Unfortunately, this test is not commercially available.

\section{Which tools are most helpful in clinical practice?}

A summary of the aforementioned riskstratification tools and biomarkers in acute pancreatitis is presented in Table 1. Although complex scoring systems such as the APACHE II are well suited to research purposes, a more simplified approach such as the BISAP is more likely to be helpful in routine clinical practice. In addition, serial measurement of blood urea nitrogen levels can be useful not only to rapidly identify patients at increased risk of death, but also to

Table 1: Tools for determining prognosis in acute pancreatitis

\begin{tabular}{|c|c|c|c|}
\hline Tool & Use & Advantages & Disadvantages \\
\hline \multicolumn{4}{|l|}{ Clinical scoring system } \\
\hline Ranson $^{1}$ & $\begin{array}{l}\text { At admission (five criteria) or after } \\
48 \mathrm{~h} \text { (six criteria) }\end{array}$ & Well-established & $\begin{array}{l}\text { Requires } 48 \mathrm{~h} \text { to complete; no } \\
\text { longer as useful in routine } \\
\text { practice }\end{array}$ \\
\hline Modified Glasgow ${ }^{2}$ & Eight factors measured over $48 \mathrm{~h}$ & $\begin{array}{l}\text { Straightforward } \\
\text { calculation }\end{array}$ & $\begin{array}{l}\text { Requires } 48 \mathrm{~h} \text { to complete, } \\
\text { limiting its use in routine } \\
\text { practice }\end{array}$ \\
\hline APACHE II ${ }^{7}$ & $\begin{array}{l}\text { Chronic health score and } 12 \\
\text { physiologic measurements }\end{array}$ & $\begin{array}{l}\text { Widely validated } \\
\text { instrument; can be done } \\
\text { at any time }\end{array}$ & $\begin{array}{l}\text { Cumbersome; not all } \\
\text { parameters routinely collected }\end{array}$ \\
\hline BISAP $^{3,11,12 *} \dagger$ & All five factors measured over $24 \mathrm{~h}$ & $\begin{array}{l}\text { Straightforward } \\
\text { calculation; can be done } \\
\text { any time during initial } \\
24 \mathrm{~h}\end{array}$ & $\begin{array}{l}\text { Static measurement (does not } \\
\text { incorporate changes over } \\
\text { time) }\end{array}$ \\
\hline $\operatorname{SIRS}^{13-15 * \ddagger}$ & Four factors measured at any time & High sensitivity & $\begin{array}{l}\text { Lacks specificity unless } \\
\text { syndrome persists }>48 \mathrm{~h}\end{array}$ \\
\hline \multicolumn{4}{|l|}{ Laboratory test } \\
\hline Blood urea nitrogen* & $\begin{array}{l}\text { Level }>7.14 \mathrm{mmol} / \mathrm{L} \text { at admission } \\
\text { or increase in level over } 24 \mathrm{hr}\end{array}$ & $\begin{array}{l}\text { Accurate, inexpensive } \\
\text { and widely available }\end{array}$ & $\begin{array}{l}\text { May reflect several disease } \\
\text { processes }\end{array}$ \\
\hline Serum creatinine* & $\begin{array}{l}\text { Increase during initial } 48 \mathrm{~h} \\
\text { associated with necrosis }\end{array}$ & $\begin{array}{l}\text { Routine test; widely } \\
\text { available }\end{array}$ & $\begin{array}{l}\text { Uncertain whether findings } \\
\text { can be extrapolated to earlier } \\
\text { time points }\end{array}$ \\
\hline C-reactive protein & $\begin{array}{l}\text { Level }>143 \mathrm{nmol} / \mathrm{L} \text { at } 48 \mathrm{~h} \text { has } \\
\text { high level of accuracy for } \\
\text { prediction of severe outcome }\end{array}$ & $\begin{array}{l}\text { Widely validated } \\
\text { biomarker; widespread } \\
\text { availability }\end{array}$ & $\begin{array}{l}\text { Peaks } 48 \mathrm{~h} \text { after onset of } \\
\text { illness }\end{array}$ \\
\hline $\begin{array}{l}\text { Inflammatory biomarkers } \\
\text { (procalcitonin, } \\
\text { polymorphonuclear elastase, } \\
\text { and interleukins } 6 \text { and 8) }\end{array}$ & $\begin{array}{l}\text { Higher levels associated with } \\
\text { severe outcome }\end{array}$ & $\begin{array}{l}\text { High degree of accuracy } \\
\text { in the early phase of } \\
\text { disease }\end{array}$ & $\begin{array}{l}\text { Not widely available; peak } \\
\text { early in the course of disease }\end{array}$ \\
\hline $\begin{array}{l}\text { Urine trypsinogen-activation } \\
\text { peptide }\end{array}$ & Urine spot measurement & $\begin{array}{l}\text { High accuracy } 24 \mathrm{~h} \text { after } \\
\text { symptom onset; validated } \\
\text { for clinical use }\end{array}$ & Not commercially available \\
\hline \multicolumn{4}{|c|}{$\begin{array}{l}\text { Note: APACHE = Acute Physiology and Ch } \\
\text { Syndrome. } \\
\text { *Most useful in routine clinical practice. } \\
\text { tSee Box } 1 \text { for definition. } \\
\text { †See Box } 2 \text { for definition. }\end{array}$} \\
\hline
\end{tabular}


potentially help guide initial fluid resuscitation efforts. Box 3 provides an example of how these tools might be used.

\section{Gaps in knowledge}

The Atlanta classification system that provided a consensus definition of severe acute pancreatitis in 1992 is currently being revised. The original system established a useful framework for researchers to evaluate prognostic factors in acute pancreatitis, but many of the criteria are now outdated. The revised criteria will incorporate our improved understanding of the nature of local complications seen in acute pancreatitis, such as the distinction between a pseudocyst and an acute necrotic collection. The revised Atlanta classification system will also formally recognize appropriate measures of severity during specific phases of illness.

Another scoring system for predicting outcome in acute pancreatitis, the Pancreatitis Outcome Prediction (POP) score, was developed using data from a retrospective cohort of 2462 patients at the time of admission to the ICU. The POP score is a good predictor of death among patients with severe acute pancreatitis (area under the ROC curve 0.84). ${ }^{6}$ However, this score has yet to be validated prospectively.

Further research is needed to help guide early resuscitation and treatment strategies in acute pancreatitis. Although current practice guidelines universally recommend agressive fluid resuscitation,

\section{Box 3: Applying the tools in clinical practice}

A 71-year-old man with a long-standing history of alcohol consumption presents to the emergency department with sudden onset of pain in his upper abdomen that extends to his back. Physical examination shows tachycardia (heart rate 115 beats/min) and tenderness in the epigastrium. A diagnosis of acute pancreatitis is confirmed by laboratory investigations that show elevated serum lipase levels (2770 IU/L; upper limit of normal, $60 \mathrm{IU} / \mathrm{L}$ ). Further laboratory investigations show leukocytosis (leukocyte count $15 \times 10^{9} / \mathrm{L}$ ), a hematocrit of $47 \%$ and mild elevation in the blood urea nitrogen level ( $8.9 \mathrm{mmol} / \mathrm{L}$; upper limit of normal, $7.85 \mathrm{mmol} / \mathrm{L})$.

Based on these results, the patient has a BISAP score of at least three points (blood urea nitrogren level $>8.9 \mathrm{mmol} / \mathrm{L}$, presence of systemic inflammatory response, age $>60 \mathrm{yr}$ ), placing him in a high-risk category.

For patients with a BISAP score of three or more, one implements a targeted fluid resuscitation protocol modeled after the Surviving Sepsis Campaign. ${ }^{27}$ In this protocol, one administers a volume challenge of $20 \mathrm{~mL} / \mathrm{kg}$ of crystalloid solution as a bolus infusion, followed by $3 \mathrm{~mL} / \mathrm{kg}$ of continuous infusion for six to eight hours. Further fluid adjustments are then made according to the changes in blood urea nitrogen levels and other clinical parameters (e.g., urine output, tachycardia).

The impact of this strategy on systemic inflammation is being evaluated in the context of a randomized-controlled trial (trial of intravenous goaldirected early fluid resuscitation [TIGER], www.clinicaltrials.gov trial no. NCT00853515). limited data is available to support these recommendations. Moreover, the type of fluid used in resuscitation may be important in terms of mitigating systemic inflammation. Finally, the potential role of early pharmacologic treatment for prevention of complications in acute pancreatitis remains an area that is markedly understudied.

\section{Conclusion}

Recent advances in determining prognosis for acute pancreatitis have centred on methods that can help guide resuscitation efforts during the crucial phase of illness (i.e., the first 24 hours after admission to hospital). Scoring systems such as the BISAP can be useful to identify patients most likely to benefit from a targeted fluid resuscitation protocol. In addition, serial measurement of routine laboratory tests such as blood urea nitrogen may help track a patient's progress during early resuscitation. Studies are currently underway that will help determine whether such objective approaches to initial management can lead to improved outcomes for patients with acute pancreatitis.

\section{References}

1. Ranson JH, Rifkind KM, Roses DF, et al. Objective early identification of severe acute pancreatitis. Am J Gastroenterol 1974;61: 443-51

2. Fagenholz PJ, Castillo CF, Harris NS, et al. Increasing United States hospital admissions for acute pancreatitis, 1988-2003. Ann Epidemiol 2007; 17:491-7.

3. Wu BU, Johannes RS, Sun X, et al. The early prediction of mortality in acute pancreatitis: a large population-based study. Gut 2008;57:1698-703.

4. Bradley EL III. A clinically based classification system for acute pancreatitis. Summary of the International Symposium on Acute Pancreatitis, Atlanta, Ga., September 11-13, 1992. Arch Surg 1993;128:586-90.

5. Brown A, Young B, Morton J, et al. Are health related outcomes in acute pancreatitis improving? An analysis of national trends in the U.S. from 1997 to 2003. JOP 2008;9:408-14.

6. Harrison DA, D'Amico G, Singer M. The Pancreatitis Outcome Prediction (POP) score: a new prognostic index for patients with severe acute pancreatitis. Crit Care Med 2007;35:1703-8.

7. Knaus WA, Draper EA, Wagner DP, Zimmerman JE. APACHE II: a severity of disease classification system. Crit Care Med 1985;13:818-29.

8. Wilson C, Heath DI, Imrie CW. Prediction of outcome in acute pancreatitis: a comparative study of APACHE II, clinical assessment and multiple factor scoring systems. Br J Surg 1990;77: 1260-4

9. Chatzicostas C, Roussomoustakaki M, Vlachonikolis IG, et al. Comparison of Ranson, APACHE II and APACHE III scoring systems in acute pancreatitis. Pancreas 2002;25:331-5.

10. Blamey SL, Imrie CW, O'Neill J, et al. Prognostic factors in acute pancreatitis. Gut 1984;25:1340-6.

11. Singh VK, Wu BU, Bollen TL, et al. A prospective evaluation of the Bedside Index for Severity in Acute Pancreatitis score in assessing mortality and intermediate markers of severity in acute pancreatitis. Am J Gastroenterol 2009;104:966-71.

12. Papachristou GI, Muddana V, Yadav D, et al. Comparison of BISAP, Ranson's, APACHE-II, and CTSI scores in predicting organ failure, complications, and mortality in acute pancreatitis. Am J Gastroenterol 2010;105:435-41.

13. Buter A, Imrie CW, Carter CR, et al. Dynamic nature of early organ dysfunction determines outcome in acute pancreatitis. Br J Surg 2002;89:298-302.

14. Mofidi R, Duff MD, Wigmore SJ, et al. Association between early systemic inflammatory response, severity of multiorgan dysfunction and death in acute pancreatitis. Br J Surg 2006;93: 738-44. 
15. Singh VK, Wu BU, Bollen TL, et al. Early systemic inflammatory response syndrome is associated with severe acute pancreatitis. Clin Gastroenterol Hepatol 2009;7:1247-51.

16. Bone RC, Sibbald WJ, Sprung CL. The ACCP-SCCM consensus conference on sepsis and organ failure. Chest 1992;101:1481-3.

17. Baillargeon JD, Orav J, Ramagopal V, et al. Hemoconcentration as an early risk factor for necrotizing pancreatitis. Am J Gastroenterol 1998;93:2130-4.

18. Brown A, Orav J, Banks PA. Hemoconcentration is an early marker for organ failure and necrotizing pancreatitis. Pancreas 2000;20:367-72.

19. Remes-Troche JM, Duarte-Rojo A, Morales G, et al. Hemoconcentration is a poor predictor of severity in acute pancreatitis. World J Gastroenterol 2005;11:7018-23.

20. Lankisch PG, Mahlke R, Blum T, et al. Hemoconcentration: An early marker of severe and/or necrotizing pancreatitis? A critical appraisal. Am J Gastroenterol 2001;96:2081-5.

21. Gardner TB, Olenec CA, Chertoff JD, et al. Hemoconcentration and pancreatic necrosis: further defining the relationship. Pancreas 2006;33:169-73.

22. Muddana V, Whitcomb DC, Khalid A, et al. Elevated serum creatinine as a marker of pancreatic necrosis in acute pancreatitis.
Am J Gastroenterol 2009;104:164-70

23. Wu BU, Johannes RS, Sun X, et al. Early changes in blood urea nitrogen predict mortality in acute pancreatitis. Gastroenterology 2009;137:129-35

24. Wu B, Bakker OJ, Papchristou GI, et al. Prognostic value of blood urea nitrogen (BUN) in the early assessment of acute pancreatitis: an international study [abstract 475p]. Gastroenterology 2010;138(Suppl 1):S-66.

25. Papachristou GI, Whitcomb DC. Inflammatory markers of disease severity in acute pancreatitis. Clin Lab Med 2005;25: 17-37

26. Neoptolemos JP, Kemppainen EA, Mayer JM, et al. Early prediction of severity in acute pancreatitis by urinary trypsinogen activation peptide: a multicentre study. Lancet 2000;355:1955-60.

27. Dellinger RP, Levy MM, Carlet JM, et al. Surviving Sepsis Campaign: international guidelines for management of severe sepsis and septic shock: 2008. Crit Care Med 2008;36:296-327.

Affiliation: Bechien $\mathrm{Wu}$ is with the Center for Pancreatic Disease, Division of Gastroenterology, Brigham and Women's Hospital, Harvard Medical School, Boston, Mass.

\section{How you can get involved in the CMA!}

The CMA is committed to providing leadership for physicians and promoting the highest standard of health and health care for Canadians. To strengthen the association and be truly representative of all Canadian physicians the CMA needs to hear from members interested in serving in elected positions and on appointed committees and advisory groups. The CMA structure comprises both governing bodies and advisory bodies either elected by General Council or appointed by the CMA Board of Directors. The Board of Directors - elected by General Council - has provincial/territorial, resident and student representation, is responsible for the overall operation of the CMA and reports to General Council on issues of governance.

CMA committees advise the Board of Directors and make recommendations on specific issues of concern to physicians and the public. Five core committees mainly consist of regional, resident and student representation while other statutory and special committees and task forces consist of individuals with interest and expertise in subject-specific fields. Positions on one or more of these committees may become available in the coming year.

For further information on how you can get involved, please contact:

\section{Jacqueline Ethier, Corporate and Governance Services \\ Canadian Medical Association \\ 1867 Alta Vista Drive, Ottawa ON K1G 5 W8 \\ Fax 613 526-7570, Tel $800663-7336$ x2249 involved@cma.ca}

By getting involved, you will have an opportunity to make a difference.

We hope to hear from you!

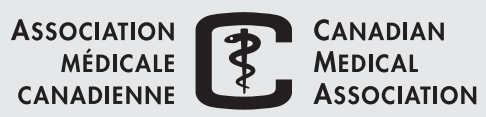

